\title{
Estimating organic, local, and other price premiums in the Hawaii fluid milk market
}

\author{
Matthew K. Loke, ${ }^{*} \dagger \mathrm{Xun} \mathrm{Xu},{ }^{*} \ddagger$ and PingSun Leung ${ }^{* 1}$ \\ ${ }^{*}$ Department of Natural Resources and Environmental Management, University of Hawaii at Mānoa, Honolulu 96822 \\ †Hawaii Department of Agriculture, Agricultural Development Division, Honolulu 96814 \\ ‡Department of Economics, University of Hawaii at Mānoa, Honolulu 96822
}

\section{ABSTRACT}

With retail scanner data, we applied hedonic price modeling to explore price premiums for organic, local, and other product attributes of fluid milk in Hawaii. Within the context of revealed preference, this analysis of organic and local attributes, under a single unified framework, is significant, as research in this area is deficient in the existing literature. This paper finds both organic and local attributes delivered price premiums over imported, conventional, whole fluid milk. However, the estimated price premium for organic milk (24.6\%) is significantly lower than findings in the existing literature. Likewise, the price premium for the local attribute is estimated at $17.4 \%$, again substantially lower compared with an earlier, stated preference study in Hawaii. Beyond that, we estimated a robust price premium of $19.7 \%$ for nutritional benefits claimed. The magnitude of this estimated coefficient reinforces the notion that nutrition information on food is deemed beneficial and valuable. Finally, package size measures the influence of product weight. With each larger package size, the estimate led to a corresponding larger price discount. This result is consistent with the practice of weight discounting that retailers usually offer with fresh packaged food. Additionally, we estimated a fairly high Armington elasticity of substitution, which suggests a relatively high degree of substitution between local and imported fluid milk when their relative price changes. Overall, this study establishes price premiums for organic, local, and nutrition benefits claimed for fluid milk in Hawaii.

Key words: scanner data, hedonic price model, fluid milk, organic, local attribute

\section{INTRODUCTION}

Organic and local food products are rapidly gaining popularity in the US market. According to the Organic

Received September 17, 2014.

Accepted January 5, 2015.

${ }^{1}$ Corresponding author: psleung@hawaii.edu
Trade Association (2010), the market share of organic food in the United States has grown from $1.2 \%$ in 2000 to $3.7 \%$ in 2009 , averaging $17 \%$ growth per annum. The availability of organic food has improved substantially, covering nearly all types of food retailers in the market place. Meanwhile, there is a growing belief that local will become the next organic in terms of customer preference (Cloud, 2007). Based on the 2008 Agricultural Resources Management Survey, Low and Vogel (2011) determined that, local food sales were 4 times larger than in the previous survey and represented $1.9 \%$ of total gross farm sales in the United States. Reflecting this trend, farmers' markets have grown more than 3 times during the past decade, quickly becoming not only regular weekly shopping events, but also great tourist destinations across North America.

As the proportion of organic and local food continues to expand, it is critical to understand how the markets are responding to their growing presence. Consumer preferences toward organic and local food products have been well documented in agricultural economics. The existing literature is stacked with studies relating to positive consumer perception and willingness to pay. Several studies have analyzed and commented on organic food (Huang and Lin, 2007; Lin et al., 2008; Smith et al., 2009), whereas other studies have focused strictly on local food (Loureiro and Hine, 2002; Carpio and Isengildina-Massa, 2009; Ulupono Initiative, 2011); however, several important issues remain unresolved.

First, most existing studies focused on fresh fruits and vegetables, whereas less attention have been devoted to dairy, meat, and other non-fresh fruit and vegetable commodities. This bias may arise because fresh produce represents the largest share of both organic and local food sales, although other products, such as dairy, also play an important role in both markets. Second, 2 approaches are commonly used to examine consumers' preferences: stated and revealed preference. Many studies used the stated preference approach, which offers the advantages of hypothetical survey choices and the inclusion of sociodemographic variables (e.g., age, sex, and income) in product analysis. One potential drawback of this approach is the unintended bias in 
estimated outcomes, resulting from the failure of consumers' responses to translate fully into their actual purchasing actions, even within a well-designed and administered stated preference survey. For example, Buzby and Skees (1994) found that among survey respondents who expressed a preference in purchasing organic produce, only a small proportion of them are actually regular purchasers.

The alternate, revealed preference approach, which often uses scanner data, can reflect consumers' actual purchases (or observed behaviors) in assessing price premiums for organic and local products. However, research efforts are often handicapped by the availability of this particular type of data set, and few studies prevail, specifically for local food. Among existing studies, Huang and Lin (2007), Lin et al. (2008), and Smith et al. (2009) provided empirical evaluation of organic price premiums for fresh produce and milk in the US market. Xu et al. (2015) and Keahiolalo (2013) analyzed the local price premiums for packaged lettuce and tomato products in Hawaii.

Third, as the market progresses, the sales of organic and local food become increasingly mingled. Consumers have expressed their desires to have both attributes in the same product (Cloud, 2007); thus, it becomes crucial to think of both attributes in the same context. Whereas the existing literature is concentrated on the study of organic and local independently, no revealed preference investigation has looked into both attributes under a single unified framework.

Our paper seeks to address these issues and start filling the corresponding research gaps. We used the Nielsen retail scanner data set and applied the hedonic price modeling approach to simultaneously explore possible organic and local price premiums of fluid milk products in Honolulu. When studying the local attribute, one further complication arises from the lack of a consensus on the definition of "local". The lack of a robust definition prohibits meaningful analyses, often blurring policy implications, and limiting potential application of the results. Several studies have adopted state boundaries as a definition for local (Jekanowski et al., 2000; Loureiro and Hine, 2002; Carpio and Isengildina-Massa, 2009). Alternatively, the Farm Act (US Government, 2008) defines 400 miles to be the maximum farm-to-table distance for local food. However, these simple geographic definitions have been questioned by researchers (Hand and Martinez, 2010; Martinez et al., 2010), as the meaning of local extends clearly to social, demographic, and other dimensions. Whereas a clear definition of local may encounter difficulties for most areas in the United States, the Hawaii market presents an unusual opportunity to study local food. The distinct geographic, cultural, and historical background of Hawaii provides a clear definition, cutoff from other markets. In Hawaii, local food refers specifically to food grown and produced in the Hawaiian Islands, in contrast to imported food, sourced from the continental United States and elsewhere.

\section{MATERIALS AND METHODS}

Scanner data tracks detailed product information with respect to price, identification code, and several other attributes when the product is being purchased at the retail store. It has been applied to an increasing number of food products in the market valuation of product characteristics (e.g., Lusk, 2010; Kim and Chung, 2011; Roheim et al., 2011).

The Nielsen scanner data set used in the current study is sourced from 3 major grocery chains (Foodland, Safeway, and Times), with a total of 19 stores in the Honolulu metropolitan area. Weekly sales of local and imported fluid milk products were recorded over a 52-wk period in 2011. Key product information contained in the data includes weekly sales amount, weekly sales units, organic origin, nutritional benefits claimed (whether product claims additional nutritional benefits), fat content (whole, $2 \%, 1 \%$, or fat-free), and package size $(8,16,32,64,96$, and $128 \mathrm{oz})$. Information on weekly sales revenue and count were combined with package size to compute the average price per pound for each product sold during the week. All Hawaii-produced milk carries a highly visible "Island Fresh" logo on its packaging and is easily recognized by consumers seeking to buy local milk.

In all, the Nielsen scanner data set contains 117 unique products with positive sale records in 2011, totaling 5,446 useable observations for analysis. Among these unique products, 6 originated from dairy farms in Hawaii, resulting in 312 observations; Table 1 presents a summary of the data set broken down into 4 categories by fat content. It can be seen that fat-free and $1 \%$ milk have the highest average prices among all categories reviewed. For the 3 categories where local products are available, a price premium against the average price of that category is observed, most notably for $2 \%$ and fat-free milk. It is also noteworthy that organic milk displays a high price premium across all 4 categories. This is consistent with results in the existing literature, indicating that the organic attribute commands a high price premium (e.g., Smith et al., 2009).

\section{Hedonic Price Model}

The hedonic analytical framework was developed by Lancaster (1966) and Rosen (1974) and proven useful for studying the quality attributes of several food prod- 
Table 1. Summary of the milk data set

\begin{tabular}{|c|c|c|c|}
\hline Item & $\begin{array}{c}\text { Average } \\
\text { price }(\$ / \mathrm{lb})\end{array}$ & $\begin{array}{c}\text { Market share (\%) } \\
\text { (weight) }\end{array}$ & $\begin{array}{c}\text { Price } \\
\text { premium }\end{array}$ \\
\hline \multicolumn{4}{|l|}{ Whole } \\
\hline All & 0.73 & 100.00 & 0.00 \\
\hline Local & 0.77 & 1.58 & 0.05 \\
\hline Import all & 0.73 & 98.42 & 0.00 \\
\hline Import nonorganic & 0.70 & 95.07 & -0.03 \\
\hline Organic & 1.47 & 3.36 & 0.74 \\
\hline \multicolumn{4}{|l|}{$2 \%$} \\
\hline All & 0.71 & 100.00 & 0.00 \\
\hline Local & 1.08 & 0.70 & 0.37 \\
\hline Import all & 0.71 & 99.30 & 0.00 \\
\hline Import nonorganic & 0.69 & 97.35 & -0.02 \\
\hline Organic & 1.47 & 1.95 & 0.76 \\
\hline \multicolumn{4}{|l|}{$1 \%$} \\
\hline All & 0.75 & 100.00 & 0.00 \\
\hline Local & $\mathrm{NA}^{2}$ & NA & NA \\
\hline Import all & 0.75 & 100.00 & 0.00 \\
\hline Import nonorganic & 0.71 & 93.65 & -0.05 \\
\hline Organic & 1.46 & 6.35 & 0.71 \\
\hline \multicolumn{4}{|l|}{ Fat-free } \\
\hline All & 0.78 & 100.00 & 0.00 \\
\hline Local & 1.10 & 1.04 & 0.31 \\
\hline Import all & 0.78 & 98.96 & 0.00 \\
\hline Import nonorganic & 0.75 & 88.05 & -0.03 \\
\hline Organic & 1.02 & 10.91 & 0.24 \\
\hline
\end{tabular}

${ }^{1}$ Price premium is calculated as the price difference against the average price of all within each category.

${ }^{2} \mathrm{NA}=$ not available.

ucts. Some of the applications include apples (Carew et al., 2012), fresh tomatoes (Huang and Lin, 2007; Keahiolalo, 2013), fresh eggs (Satimanon and Weatherspoon, 2010), frozen fish (Roheim et al., 2011), and wine (Schamel, 2006). For dairy products, Lenz et al. (1991) studied retail pricing of milk components (fat, protein, and calcium). Dimitri and Venezia (2007) investigated various aspects of the US organic milk market based on Nielsen Homescan data. Smith et al. (2009) analyzed price premiums of organic fluid milk. Alviola and Capps (2010) examined the role of demographic characteristics in the purchase of organic fluid milk.

Under the hedonic theory, an individual good is considered as a bundle of numerous attributes that are valued by consumers. Likewise, firms can adjust the quantity and attributes of the same good to maximize profits. The price of the good depends on the utility delivered by these attributes, as well as their production costs, and reflects market equilibrium, equating both consumer demand and market supply. Let $\mathbf{Z}=z_{1}$, $z_{2}, \ldots, z_{j}, \ldots, z_{n}$ be a vector of $n$ objectively measured attributes of the product; thus, the hedonic price $[P(\mathbf{Z})]$ function can be specified as:

$$
P(\mathbf{Z})=P\left(z_{1}, z_{2}, \ldots, z_{j}, \ldots, z_{n}\right) .
$$

Perfect competition is assumed where producers and consumers are price-takers with perfect information of the market. The partial derivative of the hedonic price, with respect to a particular attribute, is an implicit price that reflects both the maximum price consumers are willing to pay and the minimum price producers are willing to sell at market equilibrium. Using this information, the benchmark hedonic regression equation, using ordinary least squares (OLS), can be expressed as

$$
\ln (\text { price })=\alpha+\beta \mathbf{X}+\varepsilon,
$$

where $\mathbf{X}$ is a vector of independent variables, $\alpha$ and $\beta$ are coefficients to be estimated, and $\varepsilon$ is the error term. Following Roheim et al. (2011), the log-linear configuration is used in the estimation. The dependent variable is the logarithm of price per pound, and the independent variables include organic, local, fat content, nutritional benefits claimed, and package size, all of which are represented by indicator (binary) variables. Whereas package size can be expressed in continuous form, we opted for a binary specification instead to better capture the marginal value differences that may exist in the various package size options (see Roheim et al., 2007). Fluid milk fits nicely into this category of products that are packaged in distinct weight units.

Table 2 presents detailed descriptions of all the variables. With the average weekly price of each product being used as the basis for estimation, one concern that 
Table 2. Description of variables in hedonic regression

\begin{tabular}{llcc}
\hline Variable & Description & Mean & SD \\
\hline ln(price) & logarithm of average price per pound in dollars & 0.22 & 0.36 \\
organic & $=1$ if organic, = 0 otherwise & 0.21 & 0.41 \\
local & $=1$ if produced locally in Hawaii, $=0$ otherwise & 0.06 & 0.23 \\
whole & $=1$ if product is whole milk, = 0 otherwise & 0.24 & 0.43 \\
twopct & $=1$ if product is $2 \%$ milk, =0 otherwise & 0.29 & 0.45 \\
onepct & $=1$ if product is $1 \%$ milk, $=0$ otherwise & 0.17 & 0.37 \\
fatfree & $=1$ if product is fat-free milk, =0 otherwise & 0.31 & 0.46 \\
nutri & $=1$ if additional nutritional benefit is claimed, $=0$ otherwise & 0.12 & 0.33 \\
pkg1 & $=1$ if package size is 8 oz, $=0$ otherwise & 0.04 & 0.20 \\
pkg2 & $=1$ if package size is $16 \mathrm{oz},=0$ otherwise & 0.07 & 0.26 \\
pkg3 & $=1$ if package size is $32 \mathrm{oz},=0$ otherwise & 0.18 & 0.39 \\
pkg4 & $=1$ if package size is $48 \mathrm{oz},=0$ otherwise & 0.53 & 0.50 \\
pkg5 & $=1$ if package size is $64 \mathrm{oz},=0$ otherwise & 0.00 & 0.05 \\
pkg6 & $=1$ if package size is $128 \mathrm{oz},=0$ otherwise & 0.17 & 0.38 \\
\hline
\end{tabular}

arose was that a product with 100 weekly units sold would exert as much influence as one with 1,000 weekly units sold in the same regression. To correct for such a magnitude bias in data representation a weighted least squares (WLS) version of the hedonic price model was applied. We followed the suggestion of Diewert (2003) and adopted the square root of weekly sales amount as relevant weights.

\section{Elasticity of Substitution}

To evaluate the market interactions between different types of products, elasticity of substitution was calculated. The setup of elasticity of substitution follows the framework by Armington (1969). The model assumes that products are differentiated simply by their production origin. Accordingly, a consumer treats local and imported fluid milk as substitutes in consumption. Additionally, with the assumption that the consumer has a well-behaved utility function, the consumption decision is consistent with neoclassical theory of utility maximization.

The same consumer derives utility from a composite $(Q)$ of local $(L)$ and imported $(M)$ fluid milk. Assuming substitution possibilities between $L$ and $M$, the decision problem is to maximize utility, given prices and budget. Hence, Armington's constant elasticity of substitution utility for $Q$ can be expressed as

$$
Q=\left[\beta M^{(\sigma-1) / \sigma}+(1-\beta) L^{(\sigma-1) / \sigma}\right]^{\sigma /(\sigma-1)},
$$

where $M$ is the quantity of imported milk; $L$ is the quantity of local milk; $\sigma$ is the elasticity of substitution coefficient between local and imported milk; and $\beta$ is the distribution parameter.

The first-order condition of this problem implies that the local-to-import ratio would be a function of the price ratio to satisfy the following:

$$
M / L=\left\{[\beta /(1-\beta)]\left(P_{L} / P_{M}\right)\right\}^{\sigma} .
$$

Taking natural logarithm in Equation 4, an estimation equation is expressed as

$$
\ln (M / L)=\alpha+\sigma \ln \left[P_{L} / P_{M}\right]+\mu,
$$

where $\alpha$ and $\sigma$ are the coefficients to be estimated, with $\sigma$ being the Armington elasticity of substitution between local and imported fluid milk. The term $\alpha$ is a constant and $\mu$ is a random error.

\section{RESULTS AND DISCUSSION}

Table 3 presents the results of 2 alternate model specifications. Both hedonic regressions have substantial $R^{2}$, indicating relatively good fit of the models with the data. Most the parameter estimates are statistically significant at the $1 \%$ level. Additionally, the OLS results are comparable to the WLS in terms of magnitude and sign of the estimated coefficients. As the WLS estimates, which corrects for bias in data representation, are deemed more reliable, they constitute the principal basis for the proceeding discussions. Column 2 of Table 3 reports the benchmark regression using the WLS methodology.

The reference category in the regressions is whole milk with the following attributes: imported, conventional (nonorganic), without nutrition claims, and packaged in the smallest $(8 \mathrm{oz})$ size. The other milk categories $(2 \%, 1 \%$, and fat-free) have milk fat skimmed (varying degrees) from its original content. The results exhibit minor price variations across the different categories of milk. For example, fat-free milk shows a $3 \%$ as the estimated coefficients are dummy variables $(\beta)$ derived from a log-linear specification, an accurate percentage price change is expressed as $\left.100\left(\mathrm{e}^{\beta}-1\right)\right]$ price discount compared with the baseline (whole milk). This result is 
Table 3. Results of hedonic regressions using ordinary least squares (OLS) and weighted least squares (WLS) ${ }^{1}$

\begin{tabular}{lcc}
\hline ln(price) & $(1)$ OLS & $(2) \mathrm{WLS}$ \\
\hline organic & $0.26^{* *}$ & $0.22^{* *}$ \\
& $(0.01)$ & $(0.01)$ \\
local & $0.16^{* *}$ & $0.16^{* *}$ \\
Twopct & $(0.01)$ & $(0.01)$ \\
& 0.01 & 0.00 \\
Onepct & $(0.01)$ & $(0.01)$ \\
& 0.01 & $0.02^{*}$ \\
Fatfree & $(0.01)$ & $(0.01)$ \\
& $-0.02^{* *}$ & $-0.03^{* *}$ \\
Nutri & $(0.01)$ & $(0.01)$ \\
& $0.23^{* *}$ & $0.18^{* *}$ \\
pkg2 & $(0.01)$ & $(0.01)$ \\
& $-0.10^{* *}$ & -0.06 \\
pkg3 & $(0.02)$ & $(0.04)$ \\
& $-0.21^{* *}$ & $-0.20^{* *}$ \\
pkg4 & $(0.01)$ & $(0.02)$ \\
& $-0.48^{* *}$ & $-0.56^{* *}$ \\
pkg5 & $(0.01)$ & $(0.02)$ \\
& $-0.67^{* *}$ & $-0.64^{* *}$ \\
pkg6 & $(0.05)$ & $(0.11)$ \\
& $-0.80^{* *}$ & $-0.89^{* *}$ \\
Constant & $(0.02)$ & $(0.04)$ \\
Adjusted $\mathrm{R}^{2}$ & $0.67^{* *}$ & $0.68^{* *}$ \\
No. observed & $(0.01)$ & $(0.00)$ \\
& 0.6857 & 0.7423 \\
Nyber & 5,446 & 5,446 \\
\hline$n$
\end{tabular}

${ }^{1}$ Number in parentheses are SE of the corresponding estimated coefficients.

${ }^{*} P P<0.01 ; * P<0.05$.

consistent with previous research findings that milk fat content conveys a positive market value (e.g., Smith et al., 2009). There were moderate price premium variations for the 3 key variables: organic milk $(24.6 \%)$, local milk (17.4\%), and nutritional benefits claimed (19.7\%).

Many consumers believe that organic fluid milk is simply healthier, with better nutrition and devoid of pesticide residues, antibiotics, and artificial hormones found in the conventional product. The rising tide of demand over supply, supported with polished marketing by national chain stores, such as Whole Foods, may have driven this price premium. All other conditions being equal, organic milk enjoys a $24.6 \%$ price premium over conventional milk. Translated into monetary terms, it corresponds to a price premium of about $\$ 0.69$ per half-gallon (4 pounds). This value is lower than figures reported in the existing literature [for example, Smith et al. (2009) reported that organic premiums fall in the range from $\$ 1.23$ to $\$ 1.86$ per half-gallon for various fluid milk products]. One possible reason is that rapid expansion of the organic industry has reduced the price premiums against conventional products.

Likewise, local milk enjoys a price premium over imported whole milk. Local foods are often deemed as fresher and more flavorful. For a highly perishable product such as fluid milk, a price premium is consis- tent with the expectation that consumers are willing to pay more for healthier food with better quality. Quantitatively, it is interesting to find that the local premium (17.4\%) is comparable (though lower) to the organic premium $(24.6 \%)$. The third parameter with a robust estimated price premium of $19.7 \%$ is nutritional benefits claimed. Over time, American consumers have paid much more attention to labeling, as part of a larger social movement toward nutrition awareness in food consumption. Fluid milk, in particular, is a nutrition staple for many households with children. Milk is a good food source of protein and vitamins A, D, and $\mathrm{B}_{12}$. It is also a good source of calcium, phosphorus, and potassium. It remains a hallmark item in the food menu of our school lunch program. The magnitude of this estimated coefficient reinforces the notion that nutrition information on food is deemed beneficial and valuable.

Furthermore, the package size variables measure the influence of product weight. As expected, these variables have negative coefficients, with each larger package size corresponding to a larger price discount. This result is consistent with the practice of weight discounting that retailers usually offer with fresh packaged food.

Finally, in applying Equation 5 to measure the Armington elasticity of substitution between local and imported fluid milk, we present 2 alternate model estimates in Table 4. Both models show good fit, with high $\mathrm{R}^{2}$ and significant $t$-statistic for the parameters. The estimated coefficients in both the OLS and the generalized least squares methods are essentially similar. However, as a precaution for autocorrelation, the generalized least squares regression offers a more reliable estimator. With the generalized least squares estimation, the coefficient for the Armington elasticity of substitution is 1.56 .

This result is fairly elastic and suggests a relatively high degree of substitution between local and imported fluid milk when their relative price changes. This elasticity estimate is somewhat lower than those reported in the existing trade literature (see Donnelly et al., 2004). One explanation is that much of the trade analyses were conducted using quarterly or annual data with

Table 4. Results of Armington elasticity of substitution

\begin{tabular}{lcc}
\hline Item & $\begin{array}{c}\text { Ordinary } \\
\text { least } \\
\text { squares }\end{array}$ & $\begin{array}{c}\text { Generalized } \\
\text { least squares }\end{array}$ \\
\hline Elasticity & 1.5794 & 1.5558 \\
SE & 0.1139 & 0.1197 \\
$t$-Statistic & 13.86 & 12.99 \\
Durbin-Watson statistic & 1.7009 & 2.0547 \\
Adjusted $\mathrm{R}^{2}$ & 0.7894 & 0.7705 \\
No. observed & 52 & 51 \\
\hline
\end{tabular}


longer transaction periods, during which the effects of trade responses can often set in to establish higher substitution elasticities. In addition, the elasticity estimate was also lower than what were reported for some fresh produce. For example, Xu et al. (2015) found that elasticity for fresh packaged lettuce is above 2. This result suggests that consumers are less substitutable with respect to local and imported milk, as compared with fresh lettuce from different sources.

\section{CONCLUSIONS}

This study used hedonic price modeling and retail scanner data to estimate price premiums for organic, local, and other product attributes in the Hawaii fluid milk market. Based on our knowledge, this is the first revealed preference study that analyzes the organic and local attributes simultaneously. In recent years, the fluid milk retail market has become increasingly differentiated, in direct response to evolving consumer preferences. Our findings suggest that consumers are perceptive and influenced by product attributes such as organic, local, nutritional benefits, and package size. In Hawaii, the estimated price premium for organic milk is $24.6 \%$. Likewise, the local attribute carries a moderate price premium of $17.4 \%$. Although this value is significantly lower than the finding of $76 \%$ local premium in an earlier stated preference study in Hawaii (Ulupono Initiative, 2011), it nevertheless suggests that consumers are paying a price premium comparable to that for organic milk. Other findings include the $19.7 \%$ price premium estimated for nutritional benefits, and the contrasting price discounts associated with larger package sizes. By assessing the relative values of these attributes, local suppliers (producers, processors, and retailers) have the opportunity to offer a new or alternate marketing mix of fluid milk products. As consumers are showing an interest in fresh local milk, producers could offer more local brands with visible local labels to capture the growing market demand. Alternatively, producers could introduce more differentiated products, such as local organic milk, to meet specific consumer needs. Likewise, local processors and retailers could offer lactose-free or nutrient-enriched milk and market its underlying nutritional benefits with an appealing label. Fluid milk is often fortified with vitamins A, D, and $\mathrm{B}_{12}$, but the list has extended to vitamins $\mathrm{E}, \mathrm{K}_{2}$, and even probiotics, with claims of sustaining digestive and immune systems. The introduction of innovative, compact, and convenient packaging (including biodegradable) could provide additional utility to discerning consumers. Kosher and Halal certification may also enhance consumers' appeal in select market segments. Future research interests may include investigating the effects of individual characteristics on market choices of organic and local food by utilizing data sets that furnish information on both market transactions and household demographic variables (such as Homescan data). In addition, longitudinal scanner data, if available, may provide a link to assess possible changes in the price premium of local, organic, and other attributes, which reflect the trend in consumer preferences. Likewise, a research effort to differentiate the retail price influence of branded and private labels on fluid milk is equally appealing.

\section{ACKNOWLEDGMENTS}

The authors thank the section editor and two anonymous reviewers for helpful comments that improved the manuscript. Financial support from the Hawaii Department of Agriculture (Honolulu), the College of Tropical Agriculture and Human Resources, University of Hawaii at Mānoa (Honolulu), under the Research Supplemental Funds Program (Award No. HAW01122$\mathrm{H})$, and the USDA Agriculture and Food Research Initiative Competitive Grant No. 2011-67023-30033 from the National Institute of Food and Agriculture (Washington, DC) are gratefully acknowledged. Responsibility for the final content rests with the authors.

\section{REFERENCES}

Alviola, P. A., and O. Capps. 2010. Household demand analysis of organic and conventional fluid milk in the United States based on the 2004 Nielsen Homescan panel. Agribusiness 26:369-388.

Armington, P. S. 1969. A theory of demand for products distinguished by place of production. Staff Papers-Int. Monet. Fund 16:159 178.

Buzby, J. C., and J. R. Skees. 1994. Consumers want reduced exposure to pesticides on food. Food Rev. 17:19-22.

Carew, R., W. J. Florkowski, and E. G. Smith. 2012. Hedonic analysis of apple attributes in metropolitan markets of western Canada. Agribusiness 28:293-309.

Carpio, C. E., and O. Isengildina-Massa. 2009. Consumer willingness to pay for locally grown products: The case of South Carolina. Agribusiness 25:412-426.

Cloud, J. 2007. Eating better than organic. TIME Magazine. Accessed Jul. 24, 2014. http://www.time.com/time/magazine/ article/0,9171,1595245,00.html.

Diewert, E. 2003. Hedonic regressions: A review of some unresolved issues. Page 43 in Proc. 7th Meet. Ottawa Group, Paris, France. Accessed Jan. 28, 2015. http://www.nber.org/criw/papers/diewert.pdf.

Dimitri, C., and K. M. Venezia. 2007. Retail and Consumer Aspects of the Organic Milk Market. United States Department of Agriculture, Economic Research Service, Washington, DC.

Donnelly, W. A., K. Johnson, M. E. Tsigas, and D. Ingersoll. 2004. Revised Armington Elasticities of Substitution for the USITC Model and the Concordance for Constructing a Consistent Set for the GTAP Model. U.S. International Trade Commission, Washington, DC.

Hand, M. S., and S. Martinez. 2010. Just what does local mean? Choices (N.Y. N.Y.) 25:1-4.

Huang, C. L., and B. Lin. 2007. A hedonic analysis of fresh tomato prices among regional markets. Rev. Agric. Econ. 29:783-800. 
Jekanowski, M. D., I. I. Williams, R. Daniel, and W. A. Schiek. 2000 Consumers' willingness to purchase locally produced agricultural products: An analysis of an Indiana survey. Agric. Resour. Econ. Rev. 29:43-53.

Keahiolalo, K. 2013. Hedonic price analysis of fresh packaged tomatoes in the Honolulu market: An exploratory investigation. MA Capstone. Department of Economics, University of Hawaii at Manoa, Honolulu.

Kim, C., and C. Chung. 2011. Hedonic analysis of retail egg prices using store scanner data: An application to the Korean egg market. J. Food Distrib. Res. 42:14-27.

Lancaster, K. J. 1966. A new approach to consumer theory. J. Polit. Econ. 74:132-157.

Lenz, J. E., R. C. Mittelhammer, and J. K. Hillers. 1991. Pricing milk components at retail via hedonic analysis. J. Dairy Sci. 74:18031814.

Lin, B., T. A. Smith, and C. L. Huang. 2008. Organic premiums of US fresh produce. Renew. Agric. Food Syst. 23:208-216.

Loureiro, M. L., and S. E. Hine. 2002. Discovering niche markets: A comparison of consumer willingness to pay for local (Colorado grown), organic, and GMO-free products. J. Agric.Appl. Econ. 34:477-487.

Low, S. A., and S. Vogel. 2011. Direct and Intermediated Marketing of Local Foods in the United States. USDA, Economic Research Service, Washington DC.

Lusk, J. L. 2010. The effect of Proposition 2 on the demand for eggs in California. J. Agric. Food. Ind. Organ. 8:1-20.

Martinez, S., M. Hand, M. Da Pra, S. Pollack, K. Ralston, T. Smith, S. Vogel, S. Clark, L. Lohr, S. Low, and C. Newman. 2010. Local Food Systems: Concepts, Impacts, and Issues. USDA, Economic Research Service, Washington, DC.
Organic Trade Association. 2010 Organic industry survey. Accessed Jan. 28, 2015. http://www.thebakerynetwork.com/sites/default/ files/2010_Organic\%20Industry\%20Survey.pdf.

Roheim, C. A., F. Asche, and J. I. Santos. 2011. The elusive price premium for ecolabelled products: Evidence from seafood in the UK market. J. Agric. Econ. 62:655-668.

Roheim, C. A., L. Gardiner, and F. Asche. 2007. Value of brands and other attributes: Hedonic analysis of retail frozen fish in the UK. Mar. Resour. Econ. 22:239-253.

Rosen, S. 1974. Hedonic prices and implicit markets: Product differentiation in pure competition. J. Polit. Econ. 82:34-55.

Satimanon, T., and D. D. Weatherspoon. 2010. Hedonic analysis of sustainable food products. Int. Food Agribus. Manag. Rev. 13:5774 .

Schamel, G. 2006. Geography versus brands in a global wine market Agribusiness 22:363-374.

Smith, T. A., C. L. Huang, and B. Lin. 2009. Estimating organic premiums in the US fluid milk market. Renew. Agric. Food Syst. 24:197-204.

Ulupono Initiative. 2011. Local food market demand study of Oahu shoppers. Accessed Aug. 12, 2014. https://dl.dropboxusercontent. com/u/40878762/Local\%20Food\%20Market \%20Demand\% 20 Study\%20Executive\%20Summary.pdf.

US Government. 2008. Food, Conservation, and Energy Act of 2008 Pub. L. No. 110-234, §6015, 122 Stat. 923.

Xu, X., M. K. Loke, and P. S. Leung. 2015. Is there a price premium for local food? The case of fresh lettuce market in Hawaii. Agric. Res. Econ. Rev. In Press. 